\title{
Common co-morbidities and prescribing pattern of antibiotics in hospitalized SAM in Central India
}

\author{
Bajaj $\mathbf{N}^{1}$, Patel $\mathbf{S K}^{2}$, Singh $\mathbf{J}^{3}$, Singh $\mathbf{S P}^{4}$ \\ ${ }^{1}$ Dr Naresh Bajaj, Associate Professor, Department of Paediatrics, Gandhi Memorial Hospital, Shyam Shah Medical \\ College, APS University, Rewa, MP, India, ${ }^{2}$ Dr Saurabh Kumar Patel, NNF neonatology Fellow trainee, Little Stars \\ Children Hospital Hyderabad, Telangana, India, ${ }^{3}$ Dr Jyoti Singh, Professor \& Head, Department of Pediatrics, Gandhi \\ Memorial Hospital, Shyam Shah Medical College, APS University, Rewa, MP, India, ${ }^{4}$ Dr H P Singh. MD (Pediatrics), \\ FIAP. Professor Emeritus, Department of Pediatrics, Gandhi Memorial Hospital, Shyam Shah Medical College, APS \\ University, Rewa.MP, India.
}

Address for correspondence: Dr Saurabh Kumar Patel, Email: dr.patelsaurabh@ gmail.com

\begin{abstract}
Objective: To study the co morbidities and prescribing pattern of antibiotics in hospitalized severe acute malnourishment (SAM) children. Methods: 202 SAM children were included by simple random sampling technique Results: $46.5 \%$ SAM children had diarrhea and $21.3 \%$ of children had acute respiratory tract infections (ARTI). Ceftriaxone/cefotaxime with aminoglycosides were administered to $52.9 \%$ children whereas ampicillin and gentamicin combination were given to only $18.8 \%$ children. Conclusions: Diarrhea and ARTI are the common co-morbidities in hospitalized SAM children. Ceftriaxone/cefotaxime and aminoglycosides are the most commonly prescribed antibiotic combination. Despite epidemiological studies, more clinical and pharmacokinetic studies are needed for commonly prescribed antibiotics.
\end{abstract}

Keywords: Antibiotics, Co-morbidities, Evidences, Severe acute malnutrition.

\section{Introduction}

Malnutrition is a global problem in developing countries, particularly in children less than 5 years of age. It is estimated that nearly 20 million children have severe acute malnutrition [1]. These malnourished children often present with co-morbidities which lead to higher morbidity and mortality among under-five children in developing countries. In the absence of appropriate treatment, case-fatality rates in hospitalized children range from $30 \%$ to $50 \%$ [1,2]. World Health Organisation (WHO) issued guidelines for the management of severe acute malnutrition (SAM) which mainly focuses on hospitalized SAM [3]. The aim of the present work was to study common co-morbidities and prescribing pattern of antibiotics in hospitalized SAM in Central India.

\section{Methods}

This descriptive study was carried out in the Department of Pediatrics, Gandhi Memorial Hospital,

Manuscript received: $18^{\text {th }}$ March 2016

Reviewed: $27^{\text {th }}$ March 2016

Author Corrected; $18^{\text {th }}$ April 2016

Accepted for Publication: $30^{\text {th }}$ April 2016
Rewa from August 2012 to July 2013. All children between six to sixty months of age with severe acute malnutrition (SAM) admitted in the severe malnutrition treatment unit (SMTU) were included. WHO criteria were used to define severe acute malnutrition i. e. weight-for -height (WH) below -3 standard deviations (SD or Z-scores), or MUAC (middle upper arm circumference) $<115 \mathrm{~mm}$, or Nutritional oedema which is defined by bilateral pitting oedema [3].

Sample size estimation: Sample size was calculated using right size (China-Uganda-Zimbabwe) statistical software assuming that $n=500$ i.e. total number of patient admissions at SMTU in a year. During a one year study period, expected frequency of the SAM was presumed to be at least $20 \%$ (i.e. available prevalence of $9-15 \%$ ), thus considering $95 \%$ confidence level with $80 \%$ power and confidence interval of $5 \%$, a sample of 198 patients was required. Simple random sampling technique was used to recruit the patients who were admitted to SMTU and 202 were selected. 
Intervention: Detailed history and systemic examination were done. Life-threatening problems were identified and treated, specific deficiencies were corrected. Course of the treatment was followed and recorded.
Ethical Issues: A written, informed consent from parents and clearance from Institutional Ethics Committee (Human Studies) Shyam Shah Medical College (SSMC), Rewa was obtained prior to the start of the study.

\section{Results}

Out of 202 patients $104(51.5 \%)$ were males and 98 (48.5\%) were females. Male to female ratio was nearly equal. Maximum numbers of patients i.e. $66.3 \%$, were in age group of 6 to 12 months. Combined 6 months to 36 months constitutes about $97.5 \%$ of SAM cases studied. Diarrhea was found to be the most common co-morbid disease associated with SAM. $46.5 \%$ SAM children had diarrhea and $21.3 \%$ of children suffered acute respiratory tract infections. $7.9 \%$ children had meningitis, $6.4 \%$ had tuberculosis and only $3.9 \%$ children had malaria. (Table I).

Table I: Distribution of Co-Morbidities in the Study Population.

\begin{tabular}{|l|l|l|l|l|}
\hline \multirow{2}{*}{ Type of Disease } & \multicolumn{2}{|l|}{ Age Groups } & \multirow{2}{*}{ Total } \\
\cline { 2 - 5 } & Age $\mathbf{1 2}$ months & $\mathbf{1 2 - 2 4}$ months & $\mathbf{> 2 4}$ months & \\
\hline Acute gastroenteritis & 52 & 31 & 11 & 94 \\
\hline Acute respiratory tract infection & 30 & 10 & 3 & 43 \\
\hline Malaria & 4 & 2 & 2 & 8 \\
\hline Tuberculosis & 6 & 7 & & 13 \\
\hline Meningitis & 8 & 7 & 1 & 16 \\
\hline
\end{tabular}

All admitted children received one or other antibiotics (Table II). 18 children received oral antibiotics (cotrimoxazole or amoxycillin), of them 14 received only oral antibiotics and 4 were switched to higher parenteral antibiotics. Aminoglycosides were the most commonly used antibiotic in combinations with others. Combination of aminoglycosides and ceftriaxone/cefotaxime was given to $52.9 \%$ and that of ampicillin and aminoglycosides to $18.8 \%$ children. Vancomycin as well as meropenem were used in $11.9 \%$ children each, although they were used after using above mentioned antibiotic combinations, according to culture and sensitivity reports. Only $2.4 \%$ children received systemic antifungal.

Table II: Distribution of Antibiotics in the Study Population.

\begin{tabular}{|l|l|l|l|l|}
\hline \multirow{2}{*}{ Antibiotics } & \multicolumn{2}{|l|}{ Age Groups } & \multirow{2}{*}{ Total } \\
\cline { 2 - 4 } & Age< 12 months & $\mathbf{1 2 - 2 4}$ months & $\mathbf{2 4}$ months & 18 \\
\hline $\begin{array}{l}\text { Oral (Cotrimoxazole or } \\
\text { Amoxycillin) }\end{array}$ & 10 & 7 & 1 & 107 \\
\hline $\begin{array}{l}\text { Ceftriaxome / Cefotaxim + } \\
\text { Aminoglycosides }\end{array}$ & 61 & 35 & 11 & 38 \\
\hline Ampicillin + Aminoglycosides & 22 & 10 & 6 & 23 \\
\hline Piperacillin \& Tazobactum & 14 & 5 & 4 & 24 \\
\hline Meropenem & 15 & 8 & 1 & 24 \\
\hline Vancomycin & 12 & 8 & 4 & 1 \\
\hline Linezolide & - & - & 1 & 5 \\
\hline Fluconazole & 2 & 2 & 1 & 1 \\
\hline
\end{tabular}

\section{Discussion}

Diarrhea and acute respiratory infection were the two most common co-morbid diseases associated with SAM. Previous studies have also reported that malnourished children suffer in greater proportion from bacterial gastrointestinal and respiratory infections [4].
In a Colombian study, $68.4 \%$ of malnourished children were suffering from diarrhea at the time of admission [5]. Two African studies also showed high incidence of diarrhea in SAM children of $49 \%$ and $67 \%$ [6,7]. Though previous reports have described malnutrition as 
an important risk factor for pneumonia than for diarrhea [8].diarrhea was the major co-morbid condition found in our study. Hossain et all [9]. reported bronchopneumonia in $33 \%$, diarrhoea in $11 \%$ and pulmonary tuberculosis in $9 \%$ children.

With the implementation of WHO guidelines, low mortality rates were achieved in children with severe acute malnutrition in hospitals [10,11]. Current WHO guidelines recommend giving routine antibiotics for all children with severe acute malnutrition (SAM), even if they have uncomplicated disease with no clinically obvious infections [3]. WHO recommendation is on the basis of several epidemiological studies which have documented a high prevalence of pneumonia, bacteraemia and infections in children with malnutrition $[4,7]$. If clinical complications were present, then parenteral antibiotics were recommended [12]. For all admitted cases with any complications other than shock, meningitis or dysentery ampicillin and gentamicin are recommended. For septic shock, meningitis, dysentery and in case of no improvement ceftriaxone/cefotaxime with or without aminoglycosides is recommended [12].

We initiated management of all hospitalozed SAM children as per WHO protocol and later changed/upgraded antibiotics as per culture and sensitivity reports. In our study ampicillin and gentamicin combination were given to only $18.8 \%$ children where as ceftriaxone/cefotaxime with aminoglycosides were administer to $52.9 \%$ children. No or limited studies have been published on the efficacy, safety or pharmacokinetics of these drugs in children with SAM. Lazzerini et al quoted only one study on use of ampicillin and gentamicin that has been studied in controlled trials [13]. In spite of lack of pharmacological evidences these broad spectrum antibiotics are being increasingly used in hospitalized complicated SAM as recommended by WHO.

\section{Conclusion}

Diarrhea and acute respiratory infection are the two most common co-morbid diseases in SAM. The use of broad-spectrum antibiotics for children with SAM is supported by epidemiological data demonstrating a high prevalence of infections in these children, but clinical studies are lacking. Aminoglycosides are the most commonly used antibiotic in combinations with others. Most commonly used antibiotic combination in admitted SAM is ceftriaxone/cefotaxime and aminoglycosides followed by ampicillin and gentamicin combination in hospitalized complicated SAM. Although there are several epidemiological studies, control trials studies with regards to safety or pharmacokinetics of commonly prescribed antibiotics are needed as there is increase in use of higher antibiotics in SAM.

\section{Source of Support: Nil, Conflict of Interest: None Permission of IRB: Yes}

\section{Reference}

1. Black RE ${ }^{1}$, Allen LH, Bhutta ZA et al., Maternal and Child Undernutrition Study Group, et al. Maternal and child undernutrition: global and regional exposures and health consequences.Lancet. 2008 Jan 19;371(9608):243-60. doi: 10.1016/S01406736(07)61690-0.

2. Bhutta ZA, Ahmed T, Black RE et al., Maternal and Child Undernutrition Study Group. What works? Interventions for maternal and child undernutrition and survival Lancet. 2008 Feb 2;371(9610):417-40. doi: 10.1016/S01406736(07)61693-6.

3. World Health Organization. Management of Severe Malnutrition: A Manual for Physicians and Other Senior Health Workers, World Health Organization, Geneva, Switzerland, 1998.

4. de Onís M, Monteiro C, Akré J, Glugston G. The worldwide magnitude of protein-energy malnutrition: an overview from the WHO Global Database on Child Growth. Bull World Health Organ. 1993;71(6):70312.

5. Bernal $\mathrm{C}^{1}$, Velásquez $\mathrm{C}$, Alcaraz G, Botero J. Treatment of severe malnutrition in children: experience in implementing the World Health Organization guidelines in Turbo, Colombia. J Pediatr Gastroenterol Nutr. 2008 Mar;46(3):322-8. doi: 10.1097/MPG.0b013e318156c2c3.

6. Talbert A, Thuo N, Karisa J, Chesaro C, Ohuma E, Ignas $\mathrm{J}$, et al. Diarrhoea complicating severe acute malnutrition in Kenyan children: A prospective descriptive study of risk factors and outcome. PLoS One. 2012; 7:1. doi: 10.1371/journal.pone.0038321.

7. Irena $\mathrm{AH}$, Mwambazi M, Mulenga V. Diarrhea is a major killer of children with severe acute malnutrition 
admitted to inpatient set-up in Lusaka, Zambia. Nutr J. 2011 Oct 11;10:110. doi: 10.1186/1475-2891-10-110.

8. Berkowitz FE. Infections in children with severe protein-energy malnutrition. Pediatr Infect Dis J. 1992 Sep;11(9):750-9.

9. Hossain MI, Dodd NS, Ahmed T, Miah GM, Jamil KM, Nahar B, Alam B, Mahmood CB. Experience in managing severe malnutrition in a government tertiary treatment facility in Bangladesh. J Health Popul Nutr. 2009 Feb;27(1):72-9.

10. Bernal C, Velásquez $\mathrm{C}$, Alcaraz G, Botero J. Treatment of severe malnutrition in children: experience in implementing the World Health Organization guidelines in Turbo, Colombia. J Pediatr Gastroenterol Nutr. 2008 Mar;46(3):322-8. doi:10.1097/MPG.0b013e318156c2c3.
11. Falbo AR, Alves JG, Batista Filho M, de Fátima Costa Caminha M, Cabral-Filho JE. Decline in hospital mortality rate after the use of the World Health Organization protocol for management of severe malnutrition. Trop Doct. 2009 Apr;39(2):71-2. doi: $10.1258 /$ td.2008.080035

12. WHO. Guideline: Updates on the management of severe acute malnutrition in infants and children. Geneva: World Health Organization; 2013.

13. Lazzerini M, Tickell D. Antibiotics in severely malnourished children: systematic review of efficacy, safety and pharmacokinetics. Bull World Health Organ. 2011 Aug 1;89(8):594-607. doi: 10.2471/BLT.10.084715. Epub 2011 May 20.

\section{How to cite this article?}

Bajaj N, Patel SK, Singh J, Singh SP. Common co-morbidities and prescribing pattern of antibiotics in hospitalized SAM in Central India. Int J Pediatr Res 2016;3(5):285-288.doi:10.17511/ijpr.2016.i05.02 